\title{
INTERFACE ENTRE EDUCAÇÃO ESPECIAL E EDUCAÇÃO DE JOVENS E ADULTOS NO BRASIL E MOÇAMBIQUE
}

\author{
Samuel Vinente ${ }^{1}$, Maria da Piedade Resende da Costa ${ }^{2}$, Márcia Duarte Galvani ${ }^{3}$ \\ ${ }^{1}$ Doutorando em Educação Especial pela Universidade Federal de São Carlos - UFSCar. Técnico em Assuntos \\ Educacionais da Universidade Federal do Amazonas - UFAM. E-mail: samueljunior.ns@gmail.com \\ ${ }^{2}$ Doutora em Psicologia (Psicologia Experimental) pela Universidade de São Paulo - USP. Docente do Programa de Pós- \\ Graduação em Educação Especial da Universidade Federal de São Carlos - UFSCar. \\ ${ }^{3}$ Doutora em Educação Escolar pela Universidade Estadual Paulista Júlio de Mesquita Filho - UNESP, Araraquara, SP. \\ Docente do Programa de Pós-Graduação em Educação Especial da Universidade Federal de São Carlos - UFSCar.
}

\section{RESUMO}

A literatura internacional aponta diversas formas organizativas dos serviços de Educação Especial ao redor do mundo. O presente estudo teve como objetivo analisar a legislação educacional de Brasil e Moçambique no tocante à escolarização de jovens e adultos com deficiência. Trata-se de uma pesquisa documental realizada nos dispositivos que consubstanciam as políticas de educação especial nos países lusófonos. A busca aos documentos se deu nos sítios eletrônicos do Ministério da Educação nos respectivos países ou equivalente. Os indicadores sociais e educacionais que subsidiaram o estudo foram consultados no sítio eletrônico de Estatísticas da Comunidade dos Países de Língua Portuguesa (CPLP), publicados pelo Instituto Nacional de Estatística (INE), referentes ao ano de 2012. Foi utilizado o Protocolo de Análise Documental: legislação educacional dos países lusófonos para coleta dos dados. Observou-se com predominância, durante processo de análise documental, que a educação especial e a educação de jovens de adultos são observadas na legislação dos países como modalidade de educação escolar. Em alguns países, fica mais claro o modo explícito da Educação Especial enquanto transversal aos itens e modalidades que integram os diferentes sistemas de ensino.

Palavras-chave: Educação Especial. Política Internacional. Educação de Jovens e Adultos.

\section{INTERFACE BETWEEN SPECIAL EDUCATION AND EDUCATION OF YOUTH AND ADULTS IN BRAZIL AND MOZAMBIQUE}

ABSTRACT: The international literature points out several organizational forms of Special Education services around the world. The present study aimed to analyze the educational legislation of Brazil and Mozambique regarding the schooling of young people and adults with disabilities. It is a documentary research carried out in the devices that consubstantiate the policies of special education in Portuguesespeaking countries. The search for documents took place on the websites of the Ministry of Education in the respective countries or equivalent. The social and educational indicators that supported the study were consulted on the website of Statistics of the Community of Portuguese Speaking Countries (CPLP), published by the National Statistical Institute (INE), for the year 2012. The Protocol of Documentary Analysis : educational legislation of Portuguese-speaking countries for data collection. During documentary analysis, it was observed that special education and the education of young adults are observed in the countries' legislation as a school education modality. In some countries, the explicit way of Special Education becomes clearer as it transverse the items and modalities that integrate the different educational systems.

Keywords: Special Education. International Policy. Youth and Adult Education. 


\section{INTERFACE ENTRE EDUCACIÓN ESPECIAL Y EDUCACIÓN DE JÓVENES Y ADULTOS EN BRASIL Y MOZAMBIQUE}

RESUMÉN: La literatura internacional señala varias formas organizativas de servicios de educación especial en todo el mundo. El presente estudio tuvo como objetivo analizar la legislación educativa de Brasil y Mozambique con respecto a la escolarización de jóvenes y adultos con discapacidades. Es una investigación documental llevada a cabo en los dispositivos que confirman las políticas de educación especial en los países de habla portuguesa. La búsqueda de documentos se realizó en los sitios web del Ministerio de Educación en los respectivos países o equivalente. Los indicadores sociales y educativos que apoyaron el estudio se consultaron en el sitio web de Estadísticas de la Comunidad de Países de Lengua Portuguesa (CPLP), publicado por el Instituto Nacional de Estadística (INE), para el año 2012. El Protocolo de Análisis Documental: legislación educativa de países de habla portuguesa para la recopilación de datos. Durante el análisis documental, se observó que la educación especial y la educación de adultos jóvenes se observan en la legislación de los países como una modalidad de educación escolar. En algunos países, la forma explícita de la Educación Especial se hace más clara a medida que se trascienden a los elementos y modalidades que integran los diferentes sistemas educativos.

Palabras clave: Educación Especial. Política internacional. Educación de jóvenes y adultos.

\section{INTRODUÇÃO}

A Declaração dos Direitos das Pessoas Deficientes assegurou a esse público o direito à educação, bem como ao tratamento médico, psicológico e funcional, ao treinamento vocacional e reabilitação, à assistência, ao aconselhamento, aos serviços de inserção profissional e outros serviços que possibilitem o desenvolvimento de suas capacidades e habilidades (ONU, 1975).

A Convenção sobre Reabilitação Profissional e Emprego de Pessoas Deficientes, realizada em Genebra no ano de 1983, apresenta como finalidade que a pessoa com deficiência tenha acesso e progressão ao emprego, de modo que haja a integração ou reintegração dessas pessoas na sociedade (OIT, 1983). Observa-se então uma política pública a ser implementada nos países signatários para a empregabilidade de jovens e adultos, na qual deveriam ser consultados os empregadores e as associações representativas das pessoas com deficiência.

Já na década de 1990, a publicação da Declaração Mundial sobre Educação para Todos, decorrente de uma conferência realizada na Tailândia em 1990, assegurou no plano jurídico que a educação básica deve ser proporcionada a todas as crianças, jovens e adultos, sendo necessário universalizá-la e melhorar sua qualidade. Além disso, se torna mister oferecer a todas as crianças, jovens e adultos, a oportunidade de alcançar e manter um padrão mínimo de aprendizagem (UNESCO, 1990).
Sendo assim, pode-se verificar no âmbito da política educacional internacional uma preocupação com a escolarização de jovens e adultos, levando-se em consideração as especificidades desse público a ser atendido pelos sistemas de ensino. Decorreu dessa legislação mais ampla uma série de políticas públicas que são implementadas a partir da década de 1990 com vistas à universalização e democratização do atendimento escolar.

Em 1994 a publicação do documento referente à Conferência Mundial sobre Necessidades Educativas Especiais, realizada em Salamanca e consignada por diversos países da América Latina, determinou que a legislação dos países signatários "[...] deveria reconhecer o princípio de igualdade de oportunidade para crianças, jovens e adultos com deficiências na educação primária, secundária e terciária, sempre que possível em ambientes integrado" (UNESCO, 1994, p. 17).

O mesmo documento ratificou a urgência na garantia da educação para as "[...] crianças, jovens e adultos com necessidades educativas especiais no quadro do sistema regular de educação" (UNESCO, 1994, p. 2). No âmbito da Declaração torna-se necessário estabelecer mecanismos de planejamento, supervisão e avaliação educacional para "crianças e adultos com necessidades educativas especiais, de modo descentralizado e participativo" (UNESCO, 1994, p. 3). 
A Carta do Terceiro Milênio, aprovada em Londres no ano de 1999, ao problematizar o aumento da taxa de pessoas com deficiência no mundo, contextualizou o fracasso da prevenção de doenças evitáveis e do fracasso no tratamento das condições tratáveis (ONU, 1999). Nessa perspectiva, pode-se dizer que muitos jovens e adultos hoje com deficiência, tiveram acesso a essa condição em razão de condições sociais e ambientais desfavoráveis.

É nesse contexto, que a Carta ao Terceiro Milênio alerta quanto à necessidade de os países implementarem políticas públicas para a prevenção da deficiência e intervenção precoce às crianças e adultos que se tornaram deficientes. Torna-se necessário criar "[...] programas contínuos e de âmbito nacional para reduzir ou prevenir qualquer risco que possa causar impedimento, deficiência ou incapacidade" (ONU, 1999, p. 2).

A Convenção Interamericana para a Eliminação de todas as Formas de Discriminação Contra Pessoas Portadoras de Deficiência, ratificada pelo Brasil por meio do Decreto no 3.956/2001, convocou que os Estados comprometam-se a tomar medidas para eliminação da discriminação. Tais medidas baseiam-se em prestação ou fornecimento de bens e serviços, bem como programas, atividades e promoção da acessibilidade (BRASIL, 2001).

O Artigo 24, do Protocolo Facultativo à Convenção sobre os Direitos das Pessoas com Deficiência, ratificado pelo Brasil, assegurou no campo jurídico os direitos para o acesso ao Ensino Superior em geral, bem como treinamento profissional de acordo com a vocação, educação para adultos e formação continuada, em igualdade de condições e sem discriminação (BRASIL, 2007). Em consonância com a Organização Internacional do Trabalho, o acesso ao emprego e a inserção profissional das pessoas com deficiência na sociedade são garantidos, mais uma vez, em acordo do qual o Brasil tornouse signatário.

A Convenção Internacional sobre os Direitos das Pessoas com Deficiência, ratificado no Brasil por meio do Decreto no 6949, de 25 de agosto de 2009, apresenta como obrigação dos Estados que implementaram tal acordo, a adoção de medidas legislativas, administrativas e de qualquer outra natureza, necessárias para a realização dos direitos reconhecidos na Convenção (BRASIL, 2009).
Como se pode observar, na legislação internacional e nacional (ONU, 1975; OIT, 1983; UNESCO, 1990, 1994; ONU, 1999; BRASIL, 2001, 2007, 2009), ao longo do tempo, a legislação interna promovida por meio de acordos internacionais tem contribuído para a implementação de políticas em todas as esferas. No contexto educacional, o direito à escolarização das pessoas com deficiência tem sido tema de amplo debate pela Universidade e pelas organizações, sejam elas governamentais ou não.

Considerando-se, então, os estudos internacionais (CABRAL; MENDES, 2009; CABRAL, 2010; TANNÚS-VALADÃO, 2010), realizados no âmbito do Programa de Pós-Graduação em Educação Especial (PPGEEs), da Universidade Federal de São Carlos (UFSCar), faz-se necessária uma reflexão sobre a escolarização de jovens e adultos com deficiência, tomando como ponto de partida a lusofonia.

Acredita-se que as políticas engendradas nos diferentes países lusófonos foram e são pensadas a partir da legislação do país colonizador. Sendo assim, devido ao fato dos países, exceto Portugal, possuírem o mesmo passado de colonização e opressão, a legislação educacional desses países pode possuir similaridades no tocante à escolarização de pessoas jovens e adultas com deficiência.

Nessa perspectiva torna-se necessário investigar: (a) quais as implicações da política educacional em âmbito internacional para os países lusófonos? E, (b) como encontra-se estruturada a política de educação especial para o atendimento às necessidades de jovens e adultos com deficiência? Para isso, o presente estudo objetivou analisar a legislação educacional de Brasil e Moçambique no tocante à escolarização de jovens e adultos com deficiência.

\section{MÉTODO}

O trabalho baseou-se num processo de análise por meio da pesquisa documental, realizada nos dispositivos que consubstanciam as políticas de educação especial nos países lusófonos. Segundo Gil (2008), esse tipo de pesquisa vale-se de materiais que não receberam ainda um tratamento analítico, ou que ainda podem ser reelaborados de acordo com os objetos da pesquisa.

Em relação ao Brasil o marco principal da política educacional é a Lei de Diretrizes e Bases 
(BRASIL, 1996) e em Moçambique é a Lei do Sistema Nacional de Educação (MOÇAMBIQUE, 1992). A busca aos documentos se deu nos sítios eletrônicos do Ministério da Educação, nos respectivos países ou equivalente. Por meio da pesquisa documental, utilizaram-se como critérios de inclusão e exclusão os seguintes itens referentes aos documentos: (a) definir diretrizes e bases da educação nacional; (b) na ausência do primeiro, definir políticas educacionais para a escolarização de jovens e adultos com deficiência.

Os indicadores sociais e educacionais que subsidiaram o estudo foram consultados no sítio eletrônico de Estatísticas da Comunidade dos Países de Língua Portuguesa (CPLP), publicados pelo Instituto Nacional de Estatística (INE), referentes ao ano de 2012.
Integram o grupo dos países lusófonos: Angola, Cabo Verde, Guiné Bissau, Moçambique, São Tomé e Príncipe e Timor Leste. Somando-se, a população estimada desses países, segundo dados da Acção Local Estatística Aplicada (ALEA), varia em torno de 241.478.752 habitantes, correspondendo a $3 \%$ da população mundial.

Os indicadores sociais dos países que integram o grupo da lusofonia apontam para uma disparidade se comparados em contexto global, político e econômico. A tabela 1 apresenta os países que compõem 0 grupo com suas respectivas capitais, além da população, posição no Índice de Desenvolvimento Humano (IDH) e Gastos do Produto Interno Bruto (PIB) em educação.

Tabela 1. Caracterização dos países lusófonos quanto à população, posição no IDH e gastos do PIB com educação

\begin{tabular}{|c|c|c|c|c|c|c|}
\hline № & País & & Capital & População & $\begin{array}{l}\text { Posição no } \\
\text { IDH }\end{array}$ & $\begin{array}{l}\text { Gasto do PIB } \\
\text { com Educação }\end{array}$ \\
\hline 1 & Angola & & Luanda & 17.429 .637 & $148=(0,508)$ & $3,5 \%$ \\
\hline 2 & Brasil & & Brasília & 190.755 .799 & $85 \div(0,730)$ & $5,6 \%$ \\
\hline 3 & Cabo Verde & & Cidade da Praia & 494.039 & $132^{\circ}(0,586)$ & $5,7 \%$ \\
\hline 4 & Moçambique & & Maputo & 22.416 .881 & $185 \div(0,327)$ & $5,0 \%$ \\
\hline 5 & Portugal & & Lisboa & 10.636 .979 & $43 \circ(0,816)$ & $3,8 \%$ \\
\hline 6 & $\begin{array}{l}\text { São Tomé } \\
\text { Príncipe }\end{array}$ & $\mathrm{e}$ & São Tomé & 163.784 & $144^{\circ}(0,525)$ & $10,2 \%$ \\
\hline 7 & Timor Leste & & Dili & 1.066 .409 & $134^{\circ}(0,576)$ & n.d \\
\hline
\end{tabular}

Fonte: Aç̧ão Local Estatística Aplicada (ALEA, 2015)

Como se pode observar na tabela 1 , de um universo de 193 países reconhecidos pela Organização das Nações Unidas (ONU), muitos países que integram o grupo de lusofonia possuem dados sobre o IDH baixíssimos. Numa ordem decrescente, dos países com melhor e pior IDH verifica-se, respectivamente, Portugal (43ㅇ), Brasil (85), Cabo Verde (132) e Moçambique (185ㅇ).

Quanto ao índice populacional dos países, é necessário observar a densidade demográfica e a extensão territorial dos mesmos. 0 país mais populoso, segundo dados da Acção Local Estatística Aplicada (ALEA), seria o Brasil com 190.755.799 habitante, e o país com menor população seria São Tomé e Príncipe, com apenas 163.784 habitantes.

\section{Instrumento}

Observados os dispositivos legais dos países lusófonos, enquanto elementos de análise, tornou-se necessário a elaboração de um Protocolo para compilação e análise dos dados. Para isso, foi elaborado por Vinente e Costa (2015) um instrumento de pesquisa que se baseou em um Protocolo de Análise Documental: legislação educacional dos países lusófonos.

$$
\text { O material continha aspectos }
$$
relacionados à: (a) caracterização do documento analisado; (b) definição legal da terminologia "Jovens e Adultos"; (c) garantia do direito à educação aos jovens e adultos com deficiência; e, (d) serviços de educação especial presentes no texto legal, tais como formação de professores, 
currículo escolar, terminalidade específica, avaliação e atendimento pedagógico.

\section{RESULTADOS E DISCUSSÃO}

A seguir, considerando o quantitativo populacional dos países, apresentaremos a descrição e análise da política educacional do Brasil e, posteriormente, de Moçambique, elucidando as seguintes categorias de análise: Organização da política educacional; Definição legal da Educação Especial; Definição legal da Educação de Jovens e Adultos; Público alvo da Educação Especial; e Serviços especializados.

\section{Organização da política educacional}

Em Moçambique, o Sistema Nacional de Educação (SNE) teve a sua aprovação por intermédio da Lei no 4/1983, tendo como principal objetivo "[...] a formação do homem no quadro da construção de uma sociedade socialista" (MOÇAMBIQUE, 1983, s.p.). Em 1992, com a publicação da Lei no 06/1992, houve uma alteração na legislação educacional de Moçambique, no sentido de "[...] adequar as disposições contidas na Lei no 4/83 [...] às atuais condições sociais e econômicas do país, tanto do ponto de vista pedagógico como organizativo" (MOÇAMBIQUE, 1992, p. 1).

Em 2005, uma alteração na Constituição da República de Moçambique dispôs que a educação visa uma unidade nacional, a erradicação do analfabetismo, o domínio da ciência e da técnica, bem como a formação moral e cívica dos cidadãos. Um dos princípios previstos é de que o ensino público não é confessional, além de a Constituição mencionar que o Estado não pode programar a educação e a cultura segundo qualquer diretriz, sendo ela estética, política, ideológica ou religiosa.

O Ministério da Educação e Desenvolvimento Humano (MINED) de Moçambique é um órgão central republicano que possui as seguintes atribuições: formulação de políticas educacionais; formação e qualificação dos cidadãos; monitoramento e avaliação das atividades de educação; formação de professores e outros técnicos da educação; promoção da investigação científica, tecnológica, social e cultural; e administração do ensino técnico profissional entre outras (MOÇAMBIQUE, 2018).

No Brasil, é responsável pela política educacional o Ministério da Educação (MEC), o qual teve seu início ainda em 1930 com a fundação do Ministério dos Negócios da Educação e Saúde Pública, durante o Governo de Getúlio Vargas. O MEC é um órgão da administração federal direta que possui diversas competências, das quais se pode citar: a política nacional; a avaliação, formação e pesquisa educacional; pesquisa e extensão universitária; magistério; bem como assistência financeira a famílias carentes para escolarização de filhos e/ou dependentes (BRASIL, 2018).

No âmbito da legislação educacional brasileira vigora a Lei de Diretrizes e Bases da Educação Nacional (BRASIL, 1996) e suas respectivas alterações. Considerando a Constituição Federal, a educação é direito de todos e dever do Estado e da família, devendo ser "promovida e incentivada com a colaboração da sociedade, visando ao pleno desenvolvimento da pessoa, seu preparo para o exercício da cidadania e sua qualificação para o trabalho" (BRASIL, 1988, s.p.).

Pode-se observar com base na análise dos documentos que tanto a legislação do Brasil quanto a de Moçambique valorizam a questão do ensino público. Embora seja possível visualizar em diversos estudos as contradições na oferta de uma educação pública, gratuita, universal e laica (SILVA, 1987; SALGADO, 1985; ALMEIDA, 1998; MELLO, 1987; AFONSO, 2001; ALTMANN, 2002), esses princípios ganham força na legislação desses países.

\section{Definição legal da Educação Especial}

As políticas de Educação Especial são formuladas em Moçambique pelo Departamento de Educação Especial, um departamento autônomo sem vinculação às Secretarias. De acordo com informações do sítio eletrônico do Ministério da Educação de Moçambique, para além do ensino geral, ensino técnico-profissional e ensino superior, a Lei $n$ ㅇ 6/1992, considera o ensino especial, o ensino vocacional, o ensino de adultos, o ensino à distância e a formação dos professores como modalidades especiais que, integram o ensino escolar. Essas modalidades são regidas por disposições especiais e podem envolver outros ministérios, no caso do Ensino Especial.

O artigo 28 da Lei no 6/1992 define o ensino especial como "educação de crianças e jovens com deficiências físicas, sensoriais e mentais ou difícil enquadramento escolar" (MOÇAMBIQUE, 1992). A oferta do ensino especial era prevista na legislação de 
Moçambique por meio de classes especiais dentro das escolas regulares. Observa-se na literatura alguns estudos que se debruçaram a analisar aspectos do ensino especial no país (SANCHES; TEODORO, 2006; MASSIMACULO, 2010; CHAMBAL; BUENO, 2014; HUMBANE, 2017).

No Brasil, até início de 2019, a Diretoria de Políticas de Educação Especial era a unidade responsável pela formulação de políticas no campo da Educação Especial, estando vinculada à Secretaria de Educação Continuada, Alfabetização, Diversidade e Inclusão (SECADI). A partir de janeiro de 2019 observa-se uma nova configuração dos serviços especializado no âmbito do MEC, ficando a Educação Especial atrelada à Secretaria de Modalidades Especializadas de Educação.

$\mathrm{Na}$ legislação brasileira a educação especial é definida na LDB com redação dada pela Lei no 12.796/2013, como uma "modalidade de educação escolar oferecida preferencialmente na rede regular de ensino, para educandos com deficiência, transtornos globais do desenvolvimento e altas habilidades ou superdotação" (BRASIL, 1996). A Constituição Federal garante também no inciso III, art. 8o, o atendimento educacional especializado aos "portadores de deficiência, preferencialmente na rede regular de ensino".

Observa-se, então, na legislação educacional do Brasil e de Moçambique a oferta do atendimento na rede regular de ensino e em classes especiais também, embora atualmente a legislação brasileira não tenha dado mais tanta ênfase nos serviços especializados divergentes das classes comuns. Constatou-se ampla literatura científica em torno do atendimento educacional especializado e da análise da oferta de serviços especializados no Brasil (PADILHA, 2009; RECH, 2010; SILVA, 2013; VINENTE; MARQUES, 2015).

\section{Definição legal da Educação de Jovens e Adultos}

No tocante à Educação de Jovens e Adultos, observa-se em Moçambique uma Direcção Nacional de Alfabetização e Educação de Adultos (DINAEA) e no Brasil visualiza-se uma Diretoria de Políticas para a Juventude, Alfabetização e Educação de Jovens e Adultos no âmbito da SECADI. Em 2019, no Brasil, com as alterações realizadas pelo Governo Bolsonaro, observa-se uma nova configuração das secretarias e autarquias no âmbito do Ministério da Educação (MEC).

Verifica-se assim que tais modalidades de educação foram definidas a partir da legislação educacional de determinados países e potencializaram ao longo das últimas décadas políticas públicas para esses segmentos populacionais. Em Moçambique, o ensino de adultos é visualizado na legislação como aquele direcionado aos indivíduos que não se "encontram na idade normal de frequência dos ensinos geral e técnico-profissional".

No Brasil, a Educação de Jovens e Adultos (EJA), é destinada àqueles que não tiveram acesso ou continuidade de estudos no Ensino Fundamental e Médio na idade própria. A Lei de Diretrizes e Bases da Educação (LDB) assegura que os sistemas de ensino devem prover gratuitamente aos jovens e aos adultos, oportunidades educacionais apropriadas, consideradas as características do alunado, seus interesses, condições de vida e de trabalho, mediante cursos e exames (BRASIL, 1996).

A lei traz também no inciso $V$, do artigo 59, a questão da profissionalização para esses estudantes:

IV - educação especial
para o trabalho, visando a
sua efetiva integração na
vida em sociedade,
inclusive condições
adequadas para os que
não revelarem capacidade
de inserção no trabalho
competitivo, mediante
articulação com os órgãos
oficiais afins, bem como
para aqueles que
apresentam uma
habilidade superior nas
áreas artística, intelectual
ou psicomotora; (BRASIL,
1996).

Nesse cenário, ratificando documentos internacionais (ONU, 1975; OIT, 1983; UNESCO, 1990, 1994), a lei apresenta os termos integração, vida em sociedade e inserção. Dessa forma, a legislação trata não apenas da escolarização, mas do trabalho articulado à escolarização, pensando-se assim políticas públicas intersetoriais.

Com o avanço na legislação brasileira, a EJA se articularia preferencialmente com a Educação Profissional, de modo que haja 
articulação entre a teoria e a prática e o mundo do trabalho (BRASIL, 2008b). Na perspectiva do direito à educação, o Poder Público assume pra si o desafio de viabilizar e estimular o acesso e a permanência do trabalhador na escola, mediante ações integradas e complementares.

\section{Público-alvo da Educação Especial}

Em Moçambique, observa-se com base em sua legislação que o ensino especial seria destinado às crianças e jovens com deficiência física, bem como deficiências sensoriais e mentais. Poucas foram as alterações ao longo do processo de análise dos documentos. Ao comparar com a legislação brasileira pode-se observar que o Brasil tem uma cultura mais acentuada, no que diz respeito à alteração de dispositivos legais relacionados às diferentes esferas da vida social.

No cenário da legislação de Moçambique, as crianças com "múltiplas deficiências graves ou com atraso mental profundo" deveriam receber uma educação "adaptada às suas capacidades através do ensino extra-escolar" (MOÇAMBIQUE, 1992). Pode-se verificar uma preocupação com outras formas de atendimento especializado, além do ambiente escolar.

Além disso, mesmo tratando-se de uma legislação da década de 1990, visualiza-se um avanço relacionado à educação das pessoas com altas habilidades, devido ao fato de o sistema educativo de Moçambique prever o "ensino vocacional" na educação de jovens que "[...] demonstram especiais talentos e aptidões particulares nos domínios das ciências e das artes, educação física e outros [...]" (MOÇAMBIQUE, 1992, p. 11).

A política de Educação Especial no Brasil, atualmente, pauta-se no atendimento escolar oferecido aos estudantes com deficiência, transtornos globais do desenvolvimento e altas habilidades ou superdotação, tais estudantes constituem o chamado público-alvo da Educação Especial (BRASIL, 2008a, 2011, 2013).

No cenário brasileiro, alguns trabalhos vêm analisando a questão do encaminhamento dos estudantes aos serviços de Educação Especial (PRIETO; SOUSA, 2007; SILVA, 2010; PLETSCH, 2012; CORRÊA, 2013; SEMKIV, 2014; PIETROBOM, 2016; OLIVEIRA, 2016). Alguns desses dados fazem referência à defasagem de aprendizagem, além das condições precárias de trabalho, formação continuada insuficiente, ausência de espaços coletivos, dentre outros aspectos.
A avaliação e identificação dos estudantes que são público alvo da Educação Especial ainda carrega aspectos clínicos que categorizam as deficiências antes do encaminhamento ao serviço de Atendimento Educacional Especializado, verificando-se também a constante desarticulação entre as profissionais durante o processo avaliativo. Cada vez mais torna-se necessário realizar os seguintes questionamentos: quais os critérios que são definidos para o encaminhamento de estudantes com deficiência aos serviços de Educação Especial? Como se constitui historicamente a oferta dos serviços de Educação Especial? Quem realiza a identificação dos alunos a serem atendidos? Quais instrumentos são utilizados?

\section{Serviços especializados}

A legislação de Moçambique prevê que "[..] as formas de acesso e os planos e métodos de estudos organizados de modo distinto, tendo em conta os grupos etários a que destinam, a experiência de vida e os conhecimentos demonstrados" (MOÇAMBIQUE, 1992, p. 11).

$\mathrm{Na}$ legislação brasileira, a LDB assegura os serviços de apoio especializado, na escola regular, quando necessário. Dessa maneira, os sistemas de ensino devem assegurar a esses estudantes currículos, métodos, técnicas, recursos educativos e organização específicos (BRASIL, 1996).

É prevista a terminalidade específica no artigo 59 da lei, para aqueles que não puderem atingir o nível exigido para a conclusão do ensino fundamental, em virtude de suas deficiências, e aceleração para concluir em menor tempo o programa escolar para os superdotados (BRASIL, 1996).

\section{CONCLUSÃO}

O estudo objetivou analisar a legislação educacional do Brasil e Moçambique no tocante à escolarização dos jovens e adultos com deficiência. Revestiu-se de relevância acadêmica e social por possibilitar uma nova leitura da política de educação especial e de escolarização de jovens e adultos no Brasil e em Moçambique. Dessa forma, buscando superar a análise fragmentada da legislação nacional e dos documentos locais do Brasil, buscaram-se elementos para análise na legislação de outro país, Moçambique em questão, para elucidar temas que necessitam de um olhar comparativo externo para melhor compreensão. 
Observou-se com predominância, durante processo de análise documental, que a educação especial e a educação de jovens de adultos são observadas na legislação dos países como modalidade de educação escolar. Em alguns países, fica mais claro o modo explícito da Educação Especial enquanto transversal aos itens e modalidades que integram os diferentes sistemas de ensino.

Verificou-se que em Moçambique, o ensino de adultos é tido na legislação como aquele direcionado aos indivíduos que não se "encontram na idade normal de frequência dos ensinos geral e técnico-profissional". Enquanto no Brasil, a Educação de Jovens e Adultos (EJA), é destinada àqueles que não tiveram acesso ou continuidade de estudos no Ensino Fundamental e Médio na idade própria.

A Educação Especial vem se constituindo nos países lusófonos enquanto serviço de escolarização dos mais diferentes públicos. Para isso, torna-se necessário que as políticas educacionais se configurem enquanto elemento necessário para a universalização do atendimento escolar aos estudantes com deficiência e demais públicos que integram a clientela da Educação Especial nos diferentes países lusófonos.

O estudo apresenta como limitações o fato de a análise ser realizada apenas em documentos e diretrizes que dizem respeito ao marco legal mais importante de cada país, que se constituirá geralmente por diretrizes e bases de cada sistema educativo ou de ensino. Acredita-se que a ampliação do período delimitado ou mesmo ampliação do quantitativo de países poderá contribuir para que redes e grupos de pesquisa encontrem resultados mais significativos.

Vale ressaltar também que a utilização de entrevistas em estudos descritivos e exploratórios possibilitará que gestores e profissionais que elaboram políticas públicas de educação especial nos países possam fornecer dados relevantes para compreensão do processo de elaboração, implementação e avaliação de tais políticas. No contexto dos países lusófonos, o próprio idioma pode ser um dos fatores a favorecer a realização de mais estudos em torno do mesmo objeto de estudo, considerando que as realidades de alguns países apresentam dados semelhantes que podem ser objetos de análise.

Outra limitação desse estudo, que pode ser amplamente superado mediante realização de outras pesquisas, diz respeito à organização de educadores educacionais e sociais sobre os estudantes que compõem o público alvo da educação especial nos diferentes países. Dessa forma, taxas de matrículas, dados sobre gênero, dados evolutivos sobre desempenho acadêmico e aspectos dos serviços especializados ofertados na rede pública de ensino desses países também podem trazer contribuições para a construção do conhecimento no campo da educação especial.

Pode-se visualizar, então, um profícuo campo de estudo e pesquisa para análise e monitoramento da política educacional internacional. Sendo assim, outros estudos podem isolada ou coletivamente analisar os diferentes aspectos dos países por continente ou mesmo por acordos internacionais dos quais sejam signatários.

\section{AGRADECIMENTOS}

Ao Conselho Nacional de Desenvolvimento Científico e Tecnológico (CNPq) e à Fundação de Amparo à Pesquisa no Estado do Amazonas (FAPEAM).

\section{REFERÊNCIAS}

AFONSO, A J. Reforma do Estado e políticas educacionais: entre a crise do Estado-nação e a emergência da regulação supranacional. Educação e Sociedade, Campinas, v. 22, n. 75, p. 15-32, 2001.

ALEA. Acção Local Estatística Aplicada.2015. Disponível em: <http://www.alea.pt/html/projecto/html/project o.html>. Acesso em: 10 out. 2017.

ALMEIDA, L. F. de. Estado, nação, transnacionalização: algumas reflexões em torno do Manifesto do Partido Comunista. Revista Lutas Sociais, São Paulo, v. 4, p. 19-26, jul. 1998.

ALTMANN, H. Influências do Banco Mundial no projeto educacional brasileiro. Revista Educação e Pesquisa, São Paulo, v. 28, n. 1, p. 77-89, 2002.

BRASIL. Constituição da República Federativa do Brasil, de 5 de outubro de 1988. Diário Oficial [da] República Federativa do Brasil, Brasília, DF, 5 out. 1988. Disponível em: http://www.planalto.gov.br/ccivil 03/constituica o/constituicao.htm. Acesso em: 13 abr. 2018.

BRASIL. Lei no 9.394, de 20 de dezembro de 1996: estabelece as diretrizes e bases da educação 
nacional. Diário Oficial [da] República Federativa do Brasil, Brasília, DF, 20 dez. 1996. Disponível em:

http://www.planalto.gov.br/ccivil 03/leis/19394. htm. Acesso em: 09 set. 2018.

BRASIL. Decreto no 3.956, de 8 de outubro de 2001: Promulga a Convenção Interamericana para a Eliminação de Todas as Formas de Discriminação contra as Pessoas Portadoras de Deficiência. Diário Oficial [da] República

Federativa do Brasil, Brasília, DF, 8 out. 2001. Disponível em:

http://www.planalto.gov.br/ccivil 03/decreto/20 01/d3956.htm. Acesso em: 13 abr. 2018.

BRASIL Política Nacional de Educação Especial na Perspectiva da Educação Inclusiva. Diário Oficial [da] República Federativa do Brasil, Brasília, DF, jan. 2008a. Disponível em: http://portal.mec.gov.br/index.php?option=com docman\&view=download\&alias=16690-politicanacional-de-educacao-especial-na-perspectivada-educacao-inclusiva-05122014\&ltemid=30192. Acesso em: 08 jul. 2017.

BRASIL. Lei no 11.741, de 16 de julho de 2008: Altera dispositivos da Lei no 9.394, de 20 de dezembro de 1996, que estabelece as diretrizes e bases da educação nacional, para redimensionar, institucionalizar e integrar as ações da educação profissional técnica de nível médio, da educação de jovens e adultos e da educação profissional e tecnológica. Diário Oficial [da] República Federativa do Brasil, Brasília, DF, 16 jul. 2008b. Disponível em: http://www.planalto.gov.br/ccivil 03/ Ato20072010/2008/Lei/L11741.htm. Acesso em: 09 set. 2018.

BRASIL. Decreto no 6.949, de 25 de agosto de 2009: promulga a Convenção Internacional sobre os Direitos das Pessoas com Deficiência e seu Protocolo Facultativo, assinados em Nova York, em 30 de março de 2007. Diário Oficial da União, Brasília, DF, 25 ago. 2009. Disponível em: http://www.planalto.gov.br/ccivil 03/ Ato20072010/2009/Decreto/D6949.htm. Acesso em: 05 ago. 2017.

BRASIL. Decreto no 7.611, de 17 de novembro de 2011: dispõe sobre a educação especial, o atendimento educacional especializado e dá outras providências. Diário Oficial [da] República
Federativa do Brasil, Brasília, DF, 17 nov. 2011. Disponível em: http://www.planalto.gov.br/ccivil 03/ ato20112014/2011/decreto/d7611.htm. Acesso em: 07 jul. 2017.

BRASIL. Lei no 12.796, de 4 de abril de 2013: altera a Lei no 9.394, de 20 de dezembro de 1996, que estabelece as diretrizes e bases da educação nacional, para dispor sobre a formação dos profissionais da educação e dar outras providências. Diário Oficial [da] República Federativa do Brasil, Brasília, DF, 04 abr. 2013. Disponível em: http://www.planalto.gov.br/ccivil 03/ ato20112014/2013/lei/l12796.htm. Acesso em: 22 ago. 2017.

BRASIL. Ministério da Educação e Cultura. Secretaria de Educação Continuada, Alfabetização, Diversidade e Inclusão. 2018. Disponível em: http://portal.mec.gov.br/secretaria-de-educacaocontinuada-alfabetizacao-diversidade-einclusao/apresentacao. Acesso em: dez. 2018.

CABRAL, L. S. A. A legislação brasileira e italiana sobre Educação Especial: da década de 1970 aos dias atuais. 2010. 1216 f. Dissertação (Mestrado em Educação Especial) - Universidade Federal de São Carlos, São Carlos, 2010.

CABRAL, L. S. A.; MENDES, E. G. Da segregação da pessoa com deficiência à sua inclusão escolar radical no contexto italiano. In: JORNADA INTERNACIONAL DE POLÍTICAS PÚBLICAS, 4, 2009, São Luís. Anais [...]. São Luis: UFMA, 2009, p. 1-10.

CABRAL, L. S. A.; MENDES, E. G.; ANNA, L. Orientação acadêmica e profissional dos estudantes com deficiência nas universidades italianas. Revista Ibero-Americana de Estudos em Educação, Araraquara, v. 10, n. esp. p. 615129, 2015.

CHAMBAL, L. A.; BUENO, J. G. S. A formação de professores na perspectiva da educação inclusiva em Moçambique: uma perspectiva crítica. Cadernos CEDES, Campinas, v. 34, n. 93, p. 225239, 2014.

CORRÊA, T. C. Avaliação, diagnóstico e encaminhamento de crianças com necessidades 
educacionais especiais no sistema municipal de ensino de Londrina-PR. 2013. 126f. Dissertação (Mestrado em Educação) - Universidade Estadual de Londrina, Londrina, 2013.

GIL, A. C. Como elaborar projetos de pesquisa. 4. ed. São Paulo: Atlas, 2008.

HUMBANE, E. M. Educação e diversidade: o caso de Moçambique. Sinais, Vitória, p. 7-26, 2017.

INE. Instituto Nacional de Estatística. Estatísticas da Comunidade dos Países de Língua Portuguesa. Lisboa: INE, 2012.

KASSAR, M. C. M. Educação Especial no Brasil: desigualdades e desafios no reconhecimento da diversidade. Edu. Soc., Campinas, v. 33, n. 120, p. 833-849, jul-set, 2012.

MACHADO, I. J. R. Resenha da Obra de MARGARIDO, Alfredo. A Lusofonia e os Lusófonos: Novos Mitos Portugueses. Lisboa: Edições Universitárias Lusófonas, 2000. Disponível em: http://www.scielo.br/scielo.php?pid=S010493132002000100016\&script=sci arttext. Acesso em: 08 set. 2017.

MASSIMACULO, A. Políticas educativas para a Educação Básica em Moçambique e a diversidade cultural: o caso de escolas do município de Nampula. 2010. Dissertação (Mestrado em Educação) - Universidade do Minho, Instituto de Educação, 2010.

MELLO, G. N. (Org.). Educação e transição democrática. 5. ed. São Paulo: Cortez: Editores Associados, 1987.

MELLO, G. N. Ensino de 1ํ grau: as estratégias da transição democrática. In: MELLO, G. N. Educação e transição democrática. 5. ed. São Paulo: Cortez: Editores Associados, 1987.

MOÇAMBIQUE. Lei no 4, de 23 de março de 1983: aprova a lei do Sistema Nacional de Educação e define os princípios fundamentais na sua aplicação. Diário Oficial de Moçambique, Maputo, 23 mar. 1983.

MOÇAMBIQUE. Lei $n^{\circ}$ 6, de 6 de maio de 1992: reajusta o quadro geral do Sistema Educativo e adéqua as disposições contidas na Lei $n^{\circ} 4 / 83$, de
23 de março. Diário Oficial de Moçambique, Maputo, 6 mai. 1992.

MOÇAMBIQUE. Ministério da Educação e Desenvolvimento Humano: estrutura central. $2018 . \quad$ Disponível em: http://www.mined.gov.mz/mined/Pages/Estrutur a-Central.aspx. Acesso em: 07 dez. 2018.

OIT. Organização Internacional do Trabalho. Convenção no 159, de 1 de junho de 1983: Convenção sobre Reabilitação Profissional e Emprego de Pessoas Deficientes. Disponível em: https://www.ilo.org/brasilia/convencoes/WCMS 236165/lang--pt/index.htm. Acesso em: 18 jan. 2019.

OLIVEIRA, L. M. N. Trabalho pedagógico na Educação Especial: o professor de sala de recursos e sua implicação na escolarização dos alunos com baixa visão. 2016. 142f. Dissertação (Mestrado em Educação) - Universidade Federal de São Carlos, Sorocaba, 2016.

ONU. Organização das Nações Unidas. Carta para - Terceiro Milênio, de 9 de setembro de 1999. Disponível em: http://portal.mec.gov.br/seesp/arquivos/pdf/cart a milenio.pdf. Acesso em: 14 mar. 2018.

ONU. Organizações das Nações Unidas. Declaração dos Direitos das Pessoas Deficientes: resolução aprovada pela Assembléia Geral da Organização das Nações Unidas em 09 de dezembro de 1975, Genebra, 09 dez. 1975.

PADILHA, A. C. Projeto político-pedagógico: ações, contradições e desafios à inclusão educacional na rede municipal de Campinas/SP. 2009. 156f. Dissertação (Mestrado em Educação) - Centro de Ciências Humanas e Sociais Aplicadas, Pontifícia Universidade Católica de Campinas, Campinas, 2009.

PIETROBOM, F. O. Avaliação e encaminhamento de crianças com deficiência para o Atendimento Educacional Especializado na rede municipal de Dourados/MS. 2016. 94f. Dissertação (Mestrado em Educação) - Universidade Federal da Grande Dourados, Dourados, 2016.

PLETSCH, M. D. Educação Especial e Inclusão Escolar: uma radiografia do atendimento educacional especializado nas redes de ensino da 
Baixada Fluminense/RJ. Ciências Humanas e Sociais em Revista, v. 34, n.12, p. 31-48, jan./jun., 2012.

PRIETO, R. G. SOUSA, S. Z. L. Educação Especial: atendimentos em salas de recursos na rede municipal de São Paulo. Educação, Santa Maria, v. 32, n. 2, p. 375-396, 2007.

RECH, T. L. A emergência da inclusão escolar no Governo FHC: movimentos que tornaram uma "verdade" que permanece. 2010. $183 \mathrm{f}$. Dissertação (Mestrado em Educação) - Programa de Pós-Graduação em Educação, Universidade do Vale dos Rios dos Sinos, São Leopoldo, 2010.

RODRIGUES, D.; NOGUEIRA, J. Educação especial e inclusiva em Portugal. Revista Educación Inclusiva, Lisboa, v. 3, n. 1, p. 97-109, 2010.

SALGADO, M. U. C. Educação e transição democrática política para o ensino de 20 grau. In: MELLO, G. N. de. Educação e transição democrática. São Paulo, Cortez, 1985.

SANCHES, I.; TEODORO, A. Da integração à inclusão escolar: cruzando perspectivas e conceitos. Revista Lusófona de Educação, v. 8, p. 63-83, 2006.

SEMKIV, S. I. A. L. Análise da dinâmica de avaliação e encaminhamento de crianças com necessidades educacionais especiais num sistema municipal de ensino. 2015. 172f. Dissertação (Mestrado em Educação) Universidade Estadual do Centro-Oeste, 2015.Guarapuava-PR, 2015.

SILVA, M. F. N. Encaminhamento de alunos para salas de recursos: análise sobre os argumentos apresentados por professores de classes comuns. 2010. 146f. Dissertação (Mestrado em Educação) - Faculdade de Educação, Universidade de São Paulo, São Paulo, 2010.

SILVA, T. R. N. Melhoria da qualidade no 10 grau: o conteúdo e as condições concretas da escola. In: MELLO, G. N. (Org.). Educação e transição democrática. 5. ed. São Paulo: Cortez: Editores Associados, 1987.

SILVA, W. L. B. Políticas públicas de educação, formação de professores e inclusão de alunos com necessidades educacionais especiais: as experiências da rede pública municipal de ensino de Petrópolis/RJ. 2013. 166f. Dissertação (Mestrado em Educação) - Faculdade de Educação, Universidade Federal Fluminense. Niterói, 2013.

TANNÚS-VALADÃO, G. Planejamento educacional individualizado na Educação Especial: propostas oficiais da Itália, França, Estados Unidos e Espanha. 2010. 125f. Dissertação (Mestrado em Educação Especial) Universidade Federal de São Carlos, São Carlos, 2010.

UNESCO. Declaração Mundial sobre Educação para Todos: satisfação das necessidades básicas de aprendizagem. Jomtien: UNESCO, 1990. Disponível em: $<$ https://unesdoc.unesco.org/ark:/48223/pf0000 086291_por>. Acesso em: ago. 2018.

UNESCO. Declaração de Salamanca: sobre princípios, políticas e práticas na área das necessidades educativas especiais. Salamanca: UNESCO, $1994 . \quad$ Disponível em: <https://unesdoc.unesco.org/ark:/48223/pf0000 139394>. Acesso em: nov. 2017.

VINENTE, S.; COSTA, M. P. R. C Protocolo de Análise Documental: legislação educacional dos países lusófonos. São Carlos, UFSCar: Instrumento de Pesquisa, 2015.

VINENTE, S.; MARQUES, M. P. S. D. Atendimento Educacional Especializado: um estudo comparativo sobre a implantação das salas de recursos multifuncionais no Brasil. Revista Exitus. Santarém, v. 5, n. 1, p. 50-69, jan./jun, 2015.

Submetido: $25 / 08 / 2018$

Correções obrigatórias: 29/11/2018

Aceite final: 16/02/2019 